\title{
Commentary The evolving story of medical emergency teams in quality improvement
}

\author{
André Carlos Kajdacsy-Balla Amaral ${ }^{1}$ and Kaveh G Shojania ${ }^{2}$
}

\begin{abstract}
1Department of Critical Care Medicine, Sunnybrook Health Sciences Centre, University of Toronto, 2075 Bayview Avenue, Room D108, Toronto, ON M4N 3M5, Canada

2Department of Medicine, Sunnybrook Health Sciences Centre, University of Toronto Centre for Patient Safety, 2075 Bayview Avenue, Room H468, Toronto, ON M4N 3M5, Canada
\end{abstract}

Corresponding author: André Carlos Kajdacsy-Balla Amaral, andrecarlos.amaral@sunnybrook.ca

Published: 12 October 2009

Critical Care 2009, 13:194 (doi:10.1186/cc8033)

This article is online at http://ccforum.com/content/13/5/194

(C) 2009 BioMed Central Ltd

See related research by lyengar et al., http://ccforum.com/content/13/4/R126

\begin{abstract}
Adverse events affect approximately $3 \%$ to $12 \%$ of hospitalized patients. At least a third, but as many as half, of such events are considered preventable. Detection of these events requires investments of time and money. A report in a recent issue of Critical Care used the medical emergency team activation as a trigger to perform a prospective standardized evaluation of charts. The authors observed that roughly one fourth of calls were related to a preventable adverse event, which is comparable to the previous literature. However, while previous studies relied on retrospective chart reviews, this study introduced the novel element of real-time characterization of events by the team at the moment of consultation. This methodology captures important opportunities for improvements in local care at a rate far higher than routine incident-reporting systems, but without requiring substantial investments of additional resources. Academic centers are increasingly recognizing engagement in quality improvement as a distinct career pathway. Involving such physicians in medical emergency teams will likely facilitate the dual roles of these as a clinical outreach arm of the intensive care unit and in identifying problems in care and leading to strategies to reduce them.
\end{abstract}

Adverse events, defined as undesirable outcomes caused by medical care rather than underlying disease processes, affect approximately $3 \%$ to $12 \%$ of hospitalized patients. At least a third, but as many as half, of such events are considered preventable [1-3]. These estimates come from large national studies based on chart reviews, in which nurses look for 'flags' or 'triggers' (for example, death or unplanned admission to an intensive care unit), and physician reviewers then determine whether any adverse outcomes resulted primarily from medical care. Studies that have used direct observation or more active forms of surveillance have yielded higher rates of adverse events [4,5]. All of these detection methods require substantial investments of time and money. Moreover, especially in the case of chart review, missing information often limits the ability of reviewers to identify adverse events or judge their preventability. Thus, an efficient method for identifying adverse events which yielded sufficient clinical detail to guide assessments of preventability and did not require substantial investments of additional resources would represent a potentially powerful quality improvement tool for hospitals.

As lyengar and colleagues [1] report in a recent issue of Critical Care, medical emergency teams (METs), known widely in North America as rapid response teams, may provide just such a method. The rationale for the development of METs rose from observations that, in the majority of patients, premonitory signs and symptoms of cardiopulmonary instability are often present hours before clinical deterioration [6]. By encouraging early responses to patients with these signs, METs would presumably prevent progression to cardiopulmonary arrest. While the evidence regarding their success in improving patient outcomes remains conflicting [7,8], METs likely achieve other benefits, such as increasing nurse satisfaction and retention, and may also identify specific quality improvement targets related to recurring problems encountered [9].

By standardizing MET calls with added information on the preactivation period and performing a physician review of all cases after 1 week, lyengar and colleagues [1] were able to screen 65 MET calls over a 4-week period. They identified 23 adverse events, 16 of which were judged preventable most commonly, the failure to deliver appropriate treatment for a known diagnosis. The increased effort required for the study consisted of only a 5-minute debriefing to fill out the standardized MET form on each patient and a weekly 1-hour

MET = medical emergency team. 
meeting to review each case in order to identify clinical deteriorations that had resulted primarily from problems in antecedent care.

Two previous studies have similarly assessed MET calls as a marker for adverse events but relied entirely on retrospective chart review $[10,11]$. Reviews of all 364 MET responses over an 8-month period in an academic hospital attributed $30 \%$ of clinical deteriorations to medical errors, which were mostly diagnostic or treatment errors [10]. Root cause analysis of these cases identified 18 processes of care for quality improvement. Another study focused on MET calls for postoperative patients and judged $26 \%$ of events as definitely preventable, with an additional $47 \%$ as potentially preventable [11]. Thus, all three studies of MET calls as a means of detecting problems with the quality of care have found that approximately one quarter to one third of MET activations involve safety or quality problems. For selected patient populations (such as postoperative patients), the proportion of MET calls which reflects deficiencies in care may be even higher.

The present study introduced the novel element of real-time characterization of events by the team at the moment of consultation. This real-time assessment eliminates the resource-intensive process of retrospective chart review without requiring much effort from clinical personnel because the clinical debriefing flows naturally from the chart review that MET personnel perform to the providing of patient care.

This methodology does not replace the need for other forms of adverse event detection (such as incident reporting [12]) as it will miss events that do not involve critical clinical deteriorations (for example, many potentially catastrophic 'near misses'). It will also fail to detect problems in units not covered by METs (including the critical care unit itself). More fundamentally, the 'on-the-go' chart review process is not standardized. However, chart review processes, even for major epidemiologic studies in patient safety, suffer from wellknown problems with inter-rater disagreement [13,14], and there is no reason to expect the process used in the present study to be less reproducible than the incident investigations that hospitals currently routinely employ.

In summary, the methodology described by lyengar and colleagues [1] captures important opportunities for improvements in local care at a rate far higher than routine incidentreporting systems but without requiring substantial investments of additional resources. Moreover, the direct involvement of clinicians in the detection of patient safety and quality-of-care problems likely facilitates the crucial next step in any process for detecting adverse events, namely identifying and implementing strategies to decrease future events. Opening channels of communication between different multidisciplinary teams will also foster a culture of safety and continual improvement, instead of the (still common) avoidance of error disclosure and analysis.
Many academic centers are increasingly recognizing engagement in quality improvement as a distinct career pathway [15]. Involving such physicians in METs will likely facilitate the dual roles of METs as a clinical outreach arm of the intensive care unit and a more proactive quality improvement strategy that systematically identifies problems in care and leads to strategies to reduce them.

\section{Competing interests}

The authors declare that they have no competing interests.

\section{References}

1. lyengar A, Baxter A, Forster AJ: Using Medical Emergency Teams to detect preventable adverse events. Crit Care 2009 13:R126-R130.

2. Baker GR, Norton PG, Flintoft V, Blais R, Brown A, Cox J, Etchells E, Ghali WA, Hébert P, Majumdar SR, O'Beirne M, Palacios-Derflingher L, Reid RJ, Sheps S, Tamblyn R: The Canadian Adverse Events Study: the incidence of adverse events among hospital patients in Canada. CMAJ 2004, 170:1678-1686.

3. Committee on Quality of Health Care in America, Institute of Medicine: To Err Is Human: Building a Safer Health System. Edited by Kohn LT, Corrigan JM, Donaldson MS. Washington, DC: National Academies Press; 2000.

4. Andrews LB, Stocking C, Krizek T, Gottlieb L, Krizek C, Vargish T, Siegler M: An alternative strategy for studying adverse events in medical care. Lancet 1997, 349:309-313.

5. Forster AJ, Kyeremanteng K, Hooper J, Shojania KG, van Walraven $C$ : The impact of adverse events in the intensive care unit on hospital mortality and length of stay. BMC Health Serv Res 2008, 8:259.

6. McQuillan P, Pilkington S, Allan A, Taylor B, Short A, Morgan G, Nielsen M, Barrett D, Smith G, Collins $\mathrm{CH}$ : Confidential inquiry into quality of care before admission to intensive care. $B M J$ 1998, 316:1853-1858.

7. Ranji SR, Auerbach AD, Hurd CJ, O'Rourke K, Shojania KG: Effects of rapid response systems on clinical outcomes: systematic review and meta-analysis. J Hosp Med 2007, 2:422432.

8. Winters $\mathrm{BD}$, Pham J, Pronovost PJ: Rapid response teamswalk, don't run. JAMA 2006, 296:1645-1647.

9. King $E$, Horvath $\mathrm{R}$, Shulkin DJ: Establishing a rapid response team (RRT) in an academic hospital: one year's experience. $J$ Hosp Med 2006, 1:296-305.

10. Braithwaite RS, DeVita MA, Mahidhara R, Simmons RL, Stuart S, Foraida M: Use of medical emergency team (MET) responses to detect medical errors. Qual Saf Health Care 2004, 13:255259.

11. Kaplan LJ, Maerz LL, Schuster K, Lui F, Johnson D, Roesler D, Luckianow G, Davis KA: Uncovering system errors using a rapid response team: cross-coverage caught in the crossfire. J Trauma 2009, 67:173-178.

12. Beckmann U, Bohringer C, Carless R, Gillies DM, Runciman WB, Wu AW, Pronovost P: Evaluation of two methods for quality improvement in intensive care: facilitated incident monitoring and retrospective medical chart review. Crit Care Med 2003, 31:1006-1011.

13. Hayward RA, Hofer TP: Estimating hospital deaths due to medical errors: preventability is in the eye of the reviewer. JAMA 2001, 286:415-420.

14. Localio AR, Weaver SL, Landis JR, Lawthers AG, Brenhan TA, Hebert L, Sharp TJ: Identifying adverse events caused by medical care: degree of physician agreement in a retrospective chart review. Ann Intern Med 1996, 125:457-464.

15. Shojania KG, Levinson W: Clinicians in quality improvement: a new career pathway in academic medicine. JAMA 2009, 301: 766-768. 